\title{
Nasal nitric oxide screening for primary ciliary dyskinesia: systematic review and meta-analysis
}

\author{
Samuel A. Collins ${ }^{1,2,3}$, Kerry Gove $e^{1,2,3}$, Woolf Walker $r^{1,2,3}$ and Jane S.A. Lucas ${ }^{1,2,3}$ \\ Affiliations: 'Primary Ciliary Dyskinesia Centre, University Hospital Southampton NHS Foundation Trust, \\ Southampton, UK. ${ }^{2}$ NIHR Southampton Respiratory Biomedical Research Unit, University of Southampton \\ Faculty of Medicine and University Hospital Southampton NHS Foundation Trust, Southampton, UK. ${ }^{3}$ Academic \\ Unit of Clinical and Experimental Sciences, Faculty of Medicine, University of Southampton, Southampton, UK.
}

Correspondence: Jane S.A. Lucas, Primary Ciliary Dyskinesia Centre, Clinical and Experimental Sciences Academic Unit (Mail Point 803), University of Southampton Faculty of Medicine, University Hospital Southampton NHS Foundation Trust, Tremona Road, Southampton, S016 6YD, UK. E-mail: jlucas1dasoton.ac.uk

ABSTRACT Nasal nitric oxide (nNO) concentrations are low in patients with primary ciliary dyskinesia (PCD) providing a noninvasive screening test.

We conducted a systematic review of the literature to examine the utility of nNO in screening for PCD, in particular 1) different respiratory manoeuvres during sampling (velum closure, tidal breathing, etc.), 2) accuracy in screening young/uncooperative children, 3) stationary versus portable analysers, and 4) nNO in "atypical" PCD.

96 papers were assessed according to modified PRISMA (Preferred Reporting Items for Systematic Reviews and Meta-Analyses) criteria and 22 were included in this review.

Meta-analysis of 11 studies comparing nNO during a velum closure breath hold gave a mean \pm SD nNO of $19.4 \pm 18.6 \mathrm{~nL} \cdot \mathrm{min}^{-1}$ in PCD $(\mathrm{n}=478)$ and $265.0 \pm 118.9 \mathrm{~nL} \cdot \mathrm{min}^{-1}$ in healthy controls $(\mathrm{n}=338)$. Weighted mean difference for PCD versus healthy controls was $231.1 \mathrm{~nL} \cdot \mathrm{min}^{-1}(95 \%$ CI 193.3-268.9; $\mathrm{n}=338$ ) and $114.1 \mathrm{~nL} \cdot \mathrm{min}^{-1}(95 \%$ CI $101.5-126.8 ; \mathrm{n}=415)$ for PCD versus cystic fibrosis. Five studies of $\mathrm{nNO}$ measurement during tidal breathing demonstrated that this is an acceptable manoeuvre in young children where velum closure is not possible, but the discriminatory value was reduced. Four small studies of portable NO analysers suggest these are reliable tools for screening for PCD. However, nNO must be interpreted alongside clinical suspicion. Future studies should focus on standardising sampling techniques and reporting.

@ERSpublications

Nasal nitric oxide is a useful and increasingly versatile screening tool in primary ciliary dyskinesia at all ages http://ow.ly/AR5mq

Earn CME accreditation by answering questions about this article. You will find these at erj.ersjournals.com $/ \mathrm{misc}$ cmeinfo.xhtml

This article has supplementary material available from erj.ersjournals.com

Received: May 142014 | Accepted after revision: Aug 222014 | First published online: Oct 162014

Support statement: The National PCD Centre in Southampton is commissioned and funded by NHS England. The PCD Centre receives research funding from EU-FP7 (BESTCILIA 305404). Research in Southampton is supported by NIHR Southampton Respiratory Biomedical Research Unit and NIHR Wellcome Trust Clinical Research Facility. J.S.A. Lucas Chairs and S.A. Collins is a member of an ERS Task Force to provide a practice guideline for the diagnosis of PCD (ERS TF-2014-04)

Conflict of interest: Disclosures can be found alongside the online version of this article at erj.ersjournals.com

Copyright (OERS 2014 


\section{Introduction}

Primary ciliary dyskinesia (PCD) is a rare, autosomal recessive disease characterised by abnormal ciliary function. The resulting impaired mucus clearance from the lungs, upper airways and middle ear typically leads to respiratory symptoms from soon after birth, with ongoing chronic sinopulmonary infection and progressive loss of lung function. Approximately half of those with PCD have situs inversus and male infertility is common [1]. A European Respiratory Society (ERS) consensus statement on diagnostic techniques includes high-speed video microscopy to assess function and assessment of ciliary ultrastructure by transmission electron microscopy. Both are time-consuming, technically demanding investigations that are only available in specialist centres [2]. Difficulty accessing specialist diagnostic services frequently contributes to a delay in diagnosis [3]; therefore, an ERS PCD Task Force recommended measurement of nasal nitric oxide (nNO) as a screening test [2] to improve preselection of patients to travel to centralised diagnostic centres. A survey prior to the ERS consensus statement suggested only $46 \%$ of European PCD centres were measuring $\mathrm{nNO}[4]$.

LUNDBERG et al. [5] first reported very low levels of nNO in PCD patients in 1994, but development of nNO as a screening test was slow to establish with only a handful of studies over the next decade [6-10]. American Thoracic Society (ATS)/ERS guidelines for the measurement of nNO were published in 1999 and updated in 2005 [11]. These recommended aspiration of gas from one nostril with gas entrained via the other naris during a velum closure manoeuvre in order to avoid contamination by lower airway gases. Subsequently, a number of studies have suggested that $\mathrm{nNO}$ is not only sensitive and specific in differentiating PCD patients from healthy controls but that manoeuvres other than velum closure, which is not suitable for young children, may be discriminatory.

The mechanism by which nNO is reduced in PCD has yet to be elucidated, several hypotheses have been proposed and have been more fully reviewed elsewhere [12]. Cultured respiratory epithelial cells have been studied for their ability to synthesise NO, as well as their levels of expression of the three NO producing enzymes (nitric oxide synthases). The results have been conflicting [13-15], but cultured epithelial cells from PCD patients seem to produce equivalent amounts of NO, at baseline, as cells from non-PCD patients. Further work is needed to assess the role of the paranasal sinuses in reduced production of NO [5, 16].

The ATS/ERS guidelines recommend measurement using a stationary chemiluminescence analyser [11]; however, the recent availability of hand-held analysers with an electrochemical sensor provides a cheaper and more portable option, making screening more accessible [17]. The reliability of these portable devices has only been assessed in a handful of small studies and data from exhaled NO studies suggest readings differ between handheld and stationary devices [18]. We undertook a systematic literature review to assess the diagnostic accuracy of nNO measurement, highlighting the different analysers and respiratory manoeuvres currently used. We also considered the evidence for $\mathrm{nNO}$ as a screen for PCD in young, uncooperative children.

Our aim was to consider the effectiveness of nNO measurement as a screening tool for PCD by reviewing: 1) $\mathrm{nNO}$ measured in PCD patients compared with healthy and disease control groups using stationary analysers during a velum closure technique (as recommended in ATS/ERS guidelines [11]), including a meta-analysis; 2) nNO in patients with atypical PCD (normal electron microscopy); 3) different respiratory manoeuvres to measure $\mathrm{nNO}$ including breath holding, velum closure by forced expiration against resistance, tidal breathing and humming; 4$)$ measurement of nNO in young children ( $<5$ years) unable to cooperate with respiratory manoeuvres; and 5) reliability of handheld NO analysers for screening compared with stationary chemiluminescence analysers.

\section{Methods}

A protocol for the systematic review was developed prospectively (online supplementary material) and is briefly described in the following sections.

\section{Search strategy}

The following databases were searched from inception until April 16, 2014: MEDLINE, EMBASE, PreMEDLINE In-Process \& Other Non-Indexed Citations, Web of Knowledge Science Citation Index (SCI), Web of Knowledge ISI Proceedings and Cochrane Systematic Reviews Database. Additional references were sought through citations listed by the identified studies.

\section{Study selection}

Manuscripts were included if $\mathrm{nNO}$ was measured in PCD patients along with details of nNO sampling technique, analyser, sampling rate, patient age and method of PCD diagnosis. 
Data analysis and synthesis

The sampling rate of $\mathrm{NO}$ analysers is a determinant of $\mathrm{nNO}$ concentration. In an attempt to standardise between studies using different sampling rates we converted reported concentrations ( $\mathrm{ppb}$ ) to $\mathrm{nL} \cdot \mathrm{min}^{-1}$ using the formula $\mathrm{ppb} \times$ sampling rate $\left(\mathrm{L} \cdot \mathrm{min}^{-1}\right)$. Two studies have reported good agreement between different analysers when using this conversion estimate $[17,19]$.

Studies that reported mean $\mathrm{nNO}$ values with either standard deviation or standard error (SE/SEM) were included in the meta-analysis. Data were analysed using STATA 11.0 (StataCorp LP, College Station, TX, USA) to perform a generalised inverse variance analysis of mean difference between nNO in PCD patients and healthy or cystic fibrosis (CF) controls. We also assessed studies for heterogeneity.

\section{Results}

Study selection and risk of bias

We identified 96 publications, excluding duplicates, reporting $\mathrm{nNO}$ as an outcome in PCD patients (fig. S1). 35 were original research studies of $\mathrm{nNO}$ and were assessed for eligibility (table S1), with 22 included in the narrative synthesis and 11 in the meta-analysis (table 1).

Using QUADAS principles [27], apart from lack of blinding, the risk of bias was assessed as low for all included studies. Further details of the QUADAS criteria are given in the online supplementary material.

\section{Ability of nNO to discriminate between PCD and healthy or disease controls}

We identified 19 manuscripts that reported nNO measured by velum closure manoeuvres with a stationary analyser ( $n=634$ for PCD); of these 19 papers, 18 compared PCD with healthy controls $(n=582)$ and 11 compared PCD with CF patients $(\mathrm{n}=510)$. In addition to these 18 papers, one paper used a portable analyser to compare PCD with bronchiectasis [28]. All studies were included in the narrative synthesis and reported significantly lower nNO levels in PCD than healthy controls and CF patients (tables 1 and 2).

The meta-analysis included 478 PCD patients, 338 healthy controls and 415 patients with CF (table 1). The combined mean \pm SD $\mathrm{nNO}$ were: PCD $19.4 \pm 18.6 \mathrm{~nL} \cdot \mathrm{min}^{-1}$, healthy controls $265.0 \pm 118.9 \mathrm{~nL} \cdot \mathrm{min}^{-1}$, and

TABLE 1 Summary of studies measuring nNO in PCD, healthy control and cystic fibrosis groups using a stationary analyser with a velum closure manoeuvre

PCD

$\begin{array}{ll}\text { Subjects } n & \begin{array}{c}\text { Mean } \pm S D \\ \mathrm{~nL} \cdot \mathrm{min}^{-1}\end{array}\end{array}$

Healthy controls

\begin{tabular}{lc}
\hline Subjects $n$ & Mean \pm SD \\
$\mathrm{nL} \cdot \mathrm{min}^{-1}$
\end{tabular}

Cystic fibrosis

Subjects $n \quad$ Mean \pm SD

\section{Study}

Wodehouse et al. [9], 2003

Csoma et al. [20], 2003

NOONE et al. [21], 2004

CoRBelli et al. [10], 2004

Piacentini et al. [22], 2008

SHOEMARK et al. [23], 2009

MOREno Galdó et al. [24], 2010

MARTHIN and NIELSEN [25], 2011

Mateos-Corral et al. [26], 2011

LEIGH et al. [19], 2013

LEIGH et al. [19], 2013 ${ }^{\#}$

MARTHIN and NieLSEN [17], 2013

Combined

$\begin{array}{cr}16.4 \pm 9.2 & 16 \\ 14.9 \pm 11.8 & 14 \\ 19 \pm 17 & 27 \\ 16.4 \pm 4.35 & 24 \\ 8.9 \pm 5.7 & 26 \\ 12.3 \pm 8.6 & 20 \\ 22 \pm 29.9 & 37 \\ 19.0 \pm 13.6 & 57 \\ 17.9 \pm 13.7 & 19 \\ 20.7 \pm 24.1 & 78 \\ 23.3 \pm 18.0 & \\ 23.7 \pm 22.8 & 20 \\ 19.4 \pm 18.6 & 338\end{array}$

6
14
27
24
6
20
37
57
19
78
20

15

11

$139.5 \pm 40.7$

$126.4 \pm 62.5$

$376+124$

$268.4 \pm 138.5$

$195 \pm 92.8$

$159.8 \pm 133.5$

$224.5 \pm 37.1$

$272.4 \pm 76.0$

$366.5 \pm 131.7$

$304.6 \pm 118.8$

$267 \pm 74.4$

$265.0 \pm 118.9$
$109.5 \pm 27$

$124.8 \pm 103.7$

$138.8 \pm 84.1$

$134.0 \pm 73.5$

$150.3 \pm 58.8$

$123.2+62.7$

\begin{tabular}{lcc}
64.7 & 883.3 & 410.7 \\
58.8 & 803.0 & 373.3 \\
38.8 & 530.0 & 246.4 \\
77.6 & 1060.0 & 492.8 \\
\hline
\end{tabular}

\section{ppb equivalents ${ }^{+}$}

NIOX (Flex/MINO) ${ }^{5}$

Eco Medics CLD $88^{f}$

Sievers ${ }^{\# \#}$

LR2000"थ

nNO: nasal nitric oxide; PCD: primary ciliary dyskinesia. ${ }^{\#}$ : replication; ${ }^{\top}$ : results from co-operative healthy controls only; ${ }^{+}$: calculated by using mean in $\mathrm{nL} \cdot \mathrm{min}^{-1} /$ machine sampling rate; ${ }^{\S}$ : Aerocrine AB, Solna, Sweden; ${ }^{f}$ : Eco Medics AG, Duernten, Switzerland; ${ }^{\# \#}$ : GE Analytical Instruments, Boulder, CO, USA; ": Logan System, Rochester, UK. 
TABLE 2 Studies reporting nonparametric summary statistics for nasal nitric oxide in PCD, healthy control and cystic fibrosis groups measured via stationary analyser with velum closure manoeuvre

\begin{tabular}{|c|c|c|c|c|c|c|}
\hline Study & \multicolumn{2}{|c|}{ PCD } & \multicolumn{2}{|c|}{ Healthy controls } & \multicolumn{2}{|c|}{ Cystic fibrosis } \\
\hline KARADAG et al. [6], 1999 & 21 & $\begin{array}{c}\text { Median 13.75 } \\
\text { (range } 0.83-239.8 \text { ) }\end{array}$ & 60 & $\begin{array}{c}\text { Median } 138.3 \\
\text { (range 29-359.3) }\end{array}$ & & \\
\hline NARANG et al. [7], 2002 & 31 & $\begin{array}{c}\text { Median } 15.1 \\
\text { (range } 0.8-230 \text { ) }\end{array}$ & 53 & $\begin{array}{c}\text { Median } 179 \\
\text { (range } 99.5-359.3 \text { ) }\end{array}$ & 17 & $\begin{array}{l}\text { Median } 122.8 \\
\text { (range } 7.8-285 \text { ) }\end{array}$ \\
\hline SANTAMARIA et al. [29], 2008 & 14 & $\begin{array}{l}\text { Median 3.3 } \\
\text { (IQR 3.3) }\end{array}$ & 14 & $\begin{array}{l}\text { Median 90.1 } \\
\text { (IQR 67.2) }\end{array}$ & & \\
\hline $\begin{array}{l}\text { MARTHIN and NiELSEN [25], } \\
2011^{\#}\end{array}$ & 12 & $\begin{array}{l}\text { Median } 15.9 \\
(95 \% \mathrm{Cl} 3-162)\end{array}$ & & & & \\
\hline WALKER et al. [30], 2013 & 14 & $\begin{array}{l}\text { Median 8.1 } \\
\text { (IQR 4.8-22.8) }\end{array}$ & 18 & $\begin{array}{l}\text { Median 231.6 } \\
\text { (IQR 207-265.8) }\end{array}$ & 12 & $\begin{array}{l}\text { Median 150.3 } \\
\text { (IQR 135-182.4) }\end{array}$ \\
\hline
\end{tabular}

PCD: primary ciliary dyskinesia; IQR: interquartile range. " : consecutive referrals.

CF $123.2 \pm 62.7 \mathrm{~nL} \cdot \mathrm{min}^{-1}$. These measurements appear consistent with data from studies where nonparametric data was reported; lower median values than means are consistent with negatively skewed data (table 2).

All 11 studies in the PCD versus healthy control meta-analysis reported considerably lower levels of nNO in PCD, and this is reflected in the weighted mean difference of $231.1 \mathrm{~nL} \cdot \mathrm{min}^{-1}$ (95\% CI 193.3-268.9) (fig. 1). The difference between PCD and CF was also significant across studies, but with a smaller weighted mean difference of $114.1 \mathrm{~nL} \cdot \mathrm{min}^{-1}$ (95\% CI 101.5-126.8) (fig. 2). There was a high degree of heterogeneity, with an $\mathrm{I}^{2}$ (variation attributable to heterogeneity) of $93.9 \%$ for PCD versus healthy controls, and a moderate degree

\begin{tabular}{|c|c|c|c|c|}
\hline First author [ref.] year & & & WMD $(95 \% \mathrm{Cl}) \mathrm{nL} \cdot \mathrm{min}^{-1}$ & Weight \% \\
\hline WODEHOUSE [9] 2003 & & $\rightarrow$ & $-173.40(-191.50--155.30)$ & 9.85 \\
\hline Csoma [20] 2003 & & $\multimap$ & $-111.50(-144.78--78.22)$ & 9.34 \\
\hline NoOne [21] 2004 & $\square$ & & $-357.00(-403.96--310.04)$ & 8.72 \\
\hline CoRbelLi [10] 2004 & $\longrightarrow$ & : & $-251.96(-307.41--196.51)$ & 8.28 \\
\hline PiacentinI [22] 2008 & & - & $-186.09(-221.94--150.24)$ & 9.24 \\
\hline SHOEMARK [23] 2009 & & $\longrightarrow$ & $-147.50(-206.13--88.87)$ & 8.11 \\
\hline MoRENo GALdó [24] 2010 & & $-\rightarrow$ & $-202.50(-255.42--179.58)$ & 9.71 \\
\hline MARTHIN [25] 2011 & $\rightarrow$ & & $-253.39(-273.52--233.27)$ & 9.79 \\
\hline Mateos-Corral [26] 2011 & $\longrightarrow$ & & $-348.60(-408.12--289.08)$ & 8.06 \\
\hline LEIGH [19] 2013 & $-\square$ & & $-283.90(-310.55--257.25)$ & 9.59 \\
\hline MARTHIN [17] 2013 & $-\square$ & & $-243.30(-277.77--208.83)$ & 9.30 \\
\hline Overall $\left(\left.\right|^{2}=93.9 \%, p<0.001\right)$ & & & $-231.09(-268.91--193.27)$ & 100.00 \\
\hline Note: weights are from rand & ffects analysis & & & \\
\hline
\end{tabular}

FIGURE 1 Forest plot showing the weighted mean difference (WMD) in mean nasal nitric oxide between healthy controls and primary ciliary dyskinesia patients using a stationary analyser and velum closure technique. 
First author [ref.] year WMD $(95 \% \mathrm{CI}) \mathrm{nL} \cdot \mathrm{min}^{-1} \quad$ Weight $\%$

WODEHOUSE [9] 2003

NOONE [21] 2004

MoReno GaLdó [24] 2010

MARTHIN [25] 2011

Mateos-Corral [26] 2011

LEIGH [19] 2013

MARTHIN [17] 2013

Overall $\left({ }^{2}=40.8 \%, p=0.119\right)$

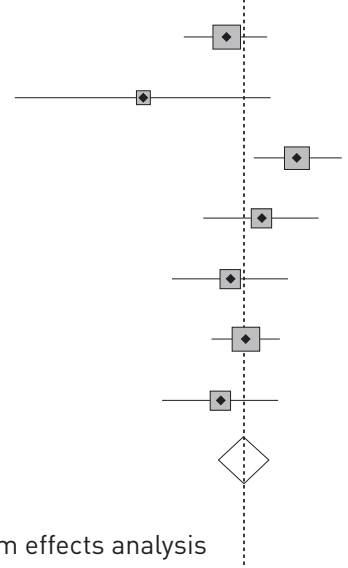

$-123.10(-143.88--102.32) \quad 18.52$

$-165.00(-229.55--100.45) \quad 3.48$

$-87.50(-109.24--65.76)$

17.68

$-105.79(-135.10--76.49)$

$-120.90(-150.65--91.15)$

$-113.30(-130.17--96.43)$

$-126.60(-154.12--99.08)$

13.45

$-114.13(-126.78--101.48) \quad 100.00$

Note: weights are from random effects analysis

$-300$

60

FIGURE 2 Forest plot showing weighted mean difference (WMD) in mean nasal nitric oxide between cystic fibrosis and primary ciliary dyskinesia patients using a stationary analyser and velum closure technique.

for PCD versus $\mathrm{CF}$ ( $\mathrm{I}^{2}$ of $40.8 \%$ ). This reflects differences in the study populations, such as age, and methodological issues such as breath hold with $\mathrm{CO}_{2}$ monitoring versus sampling during exhalation against resistance.

Nine studies calculated cut-off values with sensitivity and specificity for diagnostic accuracy within their populations (table 3). LeIGH et al. [19] developed a cut-off of $77 \mathrm{~nL} \cdot \mathrm{min}^{-1}$ using data from their centre and subsequently correctly identified 70 of 71 PCD patients $(>98 \%)$ across six other sites. This suggests that, when using standardised protocols, cut-off values are valid in different settings, analysers and populations.

Four studies reported nNO levels in consecutive referrals to a PCD diagnostic service; two were excluded (lack of sampling details and unclear PCD diagnosis) [19, 33]. ConbelLI et al. [10] reported 34 referrals, half of whom proved PCD positive; mean $\mathrm{nNO}$ for $\mathrm{PCD}$ positive patients was $16.4 \mathrm{~nL} \cdot \mathrm{min}^{-1}$ versus $159.2 \mathrm{~nL} \cdot \mathrm{min}^{-1}$ for PCD negative referrals $(\mathrm{p}<0.05)$. MARTHIN and NIELSEN [25] found a highly significant difference $(\mathrm{p}<0.0001)$ in $\mathrm{nNO}$ levels between 12 referrals whose diagnostic tests were positive and 46 whose tests were negative; medians $(95 \% \mathrm{CI})$ were $15.9(3-162) \mathrm{nL} \cdot \mathrm{min}^{-1}$ for positive versus 204.3 (34.5-386.1) $\mathrm{nL} \cdot \mathrm{min}^{-1}$ for negative results. Their cut-off of $52.5 \mathrm{~nL} \cdot \mathrm{min}^{-1}$ identified 55 out of $59 \mathrm{PCD}$ cases from consecutive referrals (sensitivity of $92 \%$, specificity of $96 \%$ ) [25].

TABLE 3 Summary of studies presenting sensitivity and specificity of their cut-off values for nNO for PCD versus healthy patients

\begin{tabular}{|c|c|c|c|c|}
\hline Study & Subjects $\mathrm{n}$ & $\mathrm{nNO}$ cut-off $\mathrm{nL} \cdot \mathrm{min}^{-1}$ & Sensitivity \% & Specificity \% \\
\hline Mateos-CoRral et al. [26], 2011" & 44 & 60.8 & 100 & 100 \\
\hline NARANG et al. [7], 2002 & 157 & 25 & 75 & 96 \\
\hline HoRVATH et al. [8], 2003 & 102 & 46.8 & 93 & 95 \\
\hline CoRbeLLI et al. [10], 2004 & 34 & 126 & 94 & 88 \\
\hline MARThin and NieLsen [25], 2011 & 94 & Breath hold 52.5 & 91.1 & 100 \\
\hline LEIGH et al. [19], 2013 & 227 & 77 & 98 & $>99.9$ \\
\hline MARTHIN and NieLSEN [17], 2013 & 57 & 78.6 & 100 & 100 \\
\hline HARRIS et al. [32], 2014 & 47 & 38 & 100 & 95 \\
\hline Boon et al. [31], 2014 & 226 & 90 & 89.5 & 87.3 \\
\hline
\end{tabular}

nNO: nasal nitric oxide; PCD: primary ciliary dyskinesia. ${ }^{\#}$ : bronchiectasis patients included in healthy control group. 
TABLE $4 \mathrm{nNO}$ values in PCD, bronchiectasis patients and healthy controls

Study

Bronchiectasis

NARANG et al. [7], 2002
HoRvATH et al. [8], 2003
Wodehouse et al. [9], 2003
WodehOuSE et al. [9], 2003"
SHOEMARK et al. [23], 2009
Moreno Galdó et al. [24], 2010
MATEOS-CoRRAL et al. [26], 2011
HARRISON et al. [28], 2012

\begin{tabular}{r}
\hline Subjects \\
21 \\
31 \\
20 \\
12 \\
20 \\
8 \\
6 \\
4
\end{tabular}

Data are presented as median (range) or mean \pm SD, unless otherwise stated. nNO: nasal nitric oxide; PCD: primary ciliary dyskinesia. ${ }^{\#}$ : Young's syndrome; ${ }^{\top}$ : measured by portable NIOX MINO analyser.

Seven studies compared nNO levels in PCD patients with those in non-CF bronchiectasis (table 4). Five reported similar nNO levels in bronchiectasis to healthy controls [7-9, 23, 26] and one used only a portable analyser in a small number of patients [28]. MORENO GALDó et al. [24] reported lower nNO in bronchiectasis than in healthy participants (mean $90.3 \mathrm{~nL} \cdot \mathrm{min}^{-1}$ versus $224.5 \mathrm{~nL} \cdot \mathrm{min}^{-1}$ ), but levels were significantly higher than in PCD patients. It is unclear why this study found bronchiectasis patients to have lower levels than those reported in other studies, but participant numbers were low [24] and the bronchiectasis group may have contained a number of undiagnosed PCD patients. PCD patients nNO was also significantly lower than patients with asthma $[19,24,30,31]$, chronic obstructive pulmonary disease (COPD) [19, 28] and humoral immunodeficiency [31].

$n N O$ in patients with atypical PCD

LEIGH et al. [19] describe 10 PCD patients with DNAH11 mutations and normal ciliary ultrastructure that all had $\mathrm{nNO}$ levels below $77 \mathrm{~nL} \cdot \mathrm{min}^{-1}$. PIFFERI et al. [34] found four patients with normal ultrastructure, but abnormal ciliary beat frequency, had nNO levels consistently below $22 \mathrm{~nL} \cdot \mathrm{min}^{-1}$ with no overlap with secondary ciliary dyskinesia or healthy subjects. KNOwLES et al. [35] recently identified patients with RSPH1 mutations causing PCD that have a milder phenotype and higher nNO levels (mean $98.3 \mathrm{~nL} \cdot \mathrm{min}^{-1}$ ). 12 of the 18 patients identified with this mutation have $\mathrm{nNO}$ above a diagnostic cut-off of $77 \mathrm{~nL} \cdot \mathrm{min}^{-1}[35,36]$. The reason for higher nNO levels in this genotype is unclear, but may provide insights into the mechanisms of low nNO in PCD.

\section{Comparison of manoeuvres used during measurement of nNO}

Four studies have compared tidal breathing with a velum closure technique (table 5). Tidal breathing produces consistently lower nNO levels in both PCD and control patients, but preserves the significant difference between PCD and other groups [17, 22, 25, 26].

Meta-analysis of three studies [17, 25, 26] gave statistically significant differences in mean nNO between tidal breathing and velum closure for healthy controls $\left(182.2 \mathrm{~nL} \cdot \mathrm{min}^{-1}\right.$ versus $278.8 \mathrm{~nL} \cdot \mathrm{min}^{-1}$; $\left.\mathrm{p}<0.0001\right)$ and $\mathrm{CF}$ patients $\left(91.5 \mathrm{~nL} \cdot \mathrm{min}^{-1}\right.$ versus $\left.132.7 \mathrm{~nL} \cdot \mathrm{min}^{-1} ; \mathrm{p}<0.0001\right)$, but not $\mathrm{PCD}\left(21.6 \mathrm{~nL} \cdot \mathrm{min}^{-1}\right.$ versus $\left.19.8 \mathrm{~nL} \cdot \mathrm{min}^{-1}\right)$. The standard deviations for PCD and controls are also larger in tidal breathing (48.6 and $\left.127.4 \mathrm{~nL} \cdot \mathrm{min}^{-1}\right)$ than in velum closure $\left(18.2\right.$ and $\left.99.4 \mathrm{~nL} \cdot \mathrm{min}^{-1}\right)$, diminishing discriminatory value.

Three studies investigated nNO levels during a humming exhalation [26, 29, 38]. Humming rapidly empties the paranasal sinuses if the osteomeatal complex is patent and causes a peak in $\mathrm{nNO}$ in healthy controls but not in PCD patients [39]. Sampling rates and methods were variable; therefore, it was not possible to reliably convert $\mathrm{ppb}$ readings to $\mathrm{nL} \cdot \mathrm{min}^{-1}$ and differences between studies should be interpreted with caution. MontelLa et al. [38] found significant differences in mean levels between PCD $(\mathrm{n}=14)$, healthy controls $(n=13)$ and CF $(n=11)$ at $5.1 \mathrm{ppb}, 165.5 \mathrm{ppb}$ and $45.6 \mathrm{ppb}$. MAteos-CorRal et al. [26] showed a significant $(\mathrm{p}<0.0001)$ difference in mean $\mathrm{nNO}$ during humming between PCD and healthy controls or CF children over 5 years of age (PCD 34.4 ppb, healthy controls 3034.9 ppb and CF 402.3 ppb; $n=20,19$ and 32 , respectively), with a $123 \mathrm{ppb}$ cut-off being $100 \%$ sensitive. SANTAMARIA et al. [29] also found a significant difference between PCD and healthy controls using humming exhalation with means of $2.8 \mathrm{ppb}$ in PCD $(n=14)$ and $212.4 \mathrm{ppb}$ in healthy controls $(n=14)$. They report a sensitivity and specificity of $100 \%$ using a nasal humming NO cut-off of $48.7 \mathrm{ppb}$. 


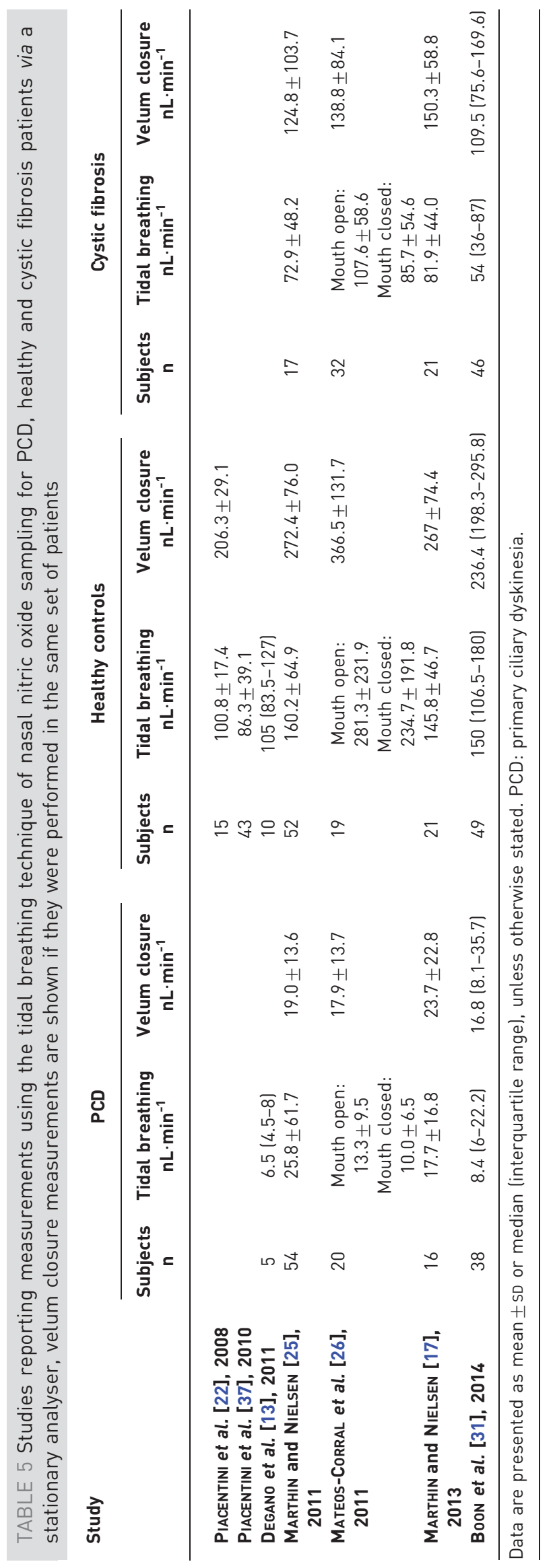


Use of nNO as a screen for PCD in young children

Very young children are unable to cooperate with specific breathing manoeuvres. Measurement during tidal breathing is, therefore, used in this age group.

BARALDI et al. [40] reported two infants that were evaluated for PCD (at 4 and 6 months of age) and compared them with five healthy infants with a mean age of almost 4 months (range 1.3-7 months). nNO levels in the two PCD patients were 9.4 and $12.7 \mathrm{~nL} \cdot \mathrm{min}^{-1}$, while the mean for the healthy controls was $32.5 \mathrm{~nL} \cdot \mathrm{min}^{-1}$ (range $24.8-41.7 \mathrm{~nL} \cdot \mathrm{min}^{-1}$ ). The lower levels in healthy controls make false positive results more likely [40]. STEHLING et al. [41] report a PCD neonate who had a nNO of less than 5 ppb on day 4 of life (sampling method not stated), while six healthy neonates (2-24 days) had a mean nNO of $171.2 \mathrm{ppb}$. MARTHIN and NieLSEN [25] reported a 16-day-old with $\mathrm{nNO}$ of $2.7 \mathrm{~nL} \cdot \mathrm{min}^{-1}$ and a 16 -week-old with $\mathrm{nNO}$ of $3.3 \mathrm{~nL} \cdot \mathrm{min}^{-1}$, both with PCD. The overall false positive rate was $39 \%$ in children under 6 years of age performing nNO during tidal breathing, nevertheless the negative predictive value was 99\% [25].

PIACENTINI et al. [22] measured nNO in two uncooperative PCD patients and 50 healthy children less than 1 year of age during tidal breathing. The two infants with PCD had nNO levels of 2.2 and $12.5 \mathrm{~nL} \cdot \mathrm{min}^{-1}$. They reported mean $\pm \mathrm{SD}$ nNO levels of $38.4 \pm 4.9 \mathrm{~nL} \cdot \mathrm{min}^{-1}$ in healthy children under 6 months of age $(\mathrm{n}=26)$ and $92.7 \pm 13.8 \mathrm{~nL} \cdot \mathrm{min}^{-1}$ for those aged $6-12 \mathrm{months}(\mathrm{n}=24)$. Their analysis showed that a cut-off of $16.2 \mathrm{~nL} \cdot \mathrm{min}^{-1}$ for less than 6 months of age had a sensitivity of $90 \%$ and specificity of $81 \%$ for diagnosis of PCD [22].

The role of portable nitric oxide meters in screening for PCD

Four studies used a portable nNO analyser; three compared this portable analyser with a stationary chemiluminescent analyser (table 6).

Montella et al. [38] assessed stationary and portable analysers in PCD, CF and healthy control patients using nasal exhalation. HARRIs et al. [32] reported that many healthy controls were unable to hold their breath for sufficient time to measure nNO using the portable device ( $45 \mathrm{~s}$ was required for sampling as opposed to $20 \mathrm{~s}$ for the stationary device), so only tidal breathing measurements were used. MARTHIN and NiELSEN [17] reported successful breath hold for 45 s by $70 \%$ of participants in their study (versus $86 \%$ for the stationary device and $100 \%$ for tidal breathing).

Portable sampling at $2 \mathrm{~mL} \cdot \mathrm{s}^{-1}$ showed no advantage over $5 \mathrm{~mL} \cdot \mathrm{s}^{-1}$ and breath hold could not be performed with the former $[17,32]$.

MARTHIN and NiELSEN [17], similar to the other three studies [28, 32, 38], confirmed significant differentiation between PCD, CF and healthy controls was obtained using the portable analyser $(\mathrm{p}<0.0001)$ using both tidal breathing and velum closure. Three studies performed receiver operating characteristic (ROC) analysis. MonTELla et al. [38] reported a cut-off of $6.9 \mathrm{~nL} \cdot \mathrm{min}^{-1}$ for silent nasal exhalation gave a sensitivity of $100 \%$ and a specificity of $85 \%$ to detect patients with PCD. HARRIS et al. [32] reported a cut-off

TABLE 6 Summary of studies reporting nasal nitric oxide measurements with a portable nitric oxide analyser in PCD, healthy controls and cystic fibrosis patients, readings from a stationary analyser are shown for comparison if they were measured

\begin{tabular}{|c|c|c|c|c|c|c|}
\hline Study & \multicolumn{2}{|c|}{ PCD } & \multicolumn{2}{|c|}{ Healthy controls } & \multicolumn{2}{|c|}{ Cystic fibrosis } \\
\hline HARRISON et al. [28], 2012 & & $\begin{array}{c}\text { Mean } \pm S D \\
7.2 \pm 4.1 \\
n=4\end{array}$ & & $\begin{array}{c}\text { Mean } \pm S D \\
125.7 \pm 22.8 \\
n=5\end{array}$ & & $\begin{array}{c}\text { Mean } \pm \text { SD } \\
12 \pm 11.7 \\
n=6\end{array}$ \\
\hline Marthin and Nielsen [17], & Mean \pm SD & Mean \pm SD & Mean \pm SD & Mean \pm SD & Mean $\pm S D$ & Mean \pm SD \\
\hline $2013^{+}$ & $\begin{array}{c}23.7 \pm 22.8 \\
n=16\end{array}$ & $\begin{array}{c}19.2 \pm 18.7 \\
n=12\end{array}$ & $\begin{array}{c}267 \pm 74.4 \\
n=20\end{array}$ & $\begin{array}{c}180.9 \pm 57.7 \\
n=21\end{array}$ & $\begin{array}{c}150.3 \pm 58.8 \\
n=21\end{array}$ & $\begin{array}{c}97.2 \pm \overline{41} .6 \\
n=8\end{array}$ \\
\hline HARRIS et al. [32], $2014^{\S}$ & $\begin{array}{c}\text { Median } 12.3 \\
\text { (IQR 8.4) } \\
n=11\end{array}$ & $\begin{array}{l}\text { Median } 5.4 \\
\text { (IQR 3.3) } \\
n=12\end{array}$ & $\begin{array}{c}\text { Median } 208.2 \\
\text { (IQR 58.8), } \\
n=15\end{array}$ & $\begin{array}{c}\text { Median } 112.6 \\
\text { (IQR 88.0), } \\
n=15\end{array}$ & & \\
\hline
\end{tabular}

All nasal nitric oxide measurements have units of $\mathrm{nL} \cdot \mathrm{min}^{-1}$. PCD: primary ciliary dyskinesia; IQR: interquartile range. ${ }^{\#}$ : nasal exhalation; ${ }^{\circ}$ : tidal breathing; ${ }^{+}$: breath hold; ${ }^{\text {s }}$ : tidal breathing (MINO Breathhold - Flex). 
of $30 \mathrm{~nL} \cdot \mathrm{min}^{-1}$ had $100 \%$ sensitivity and $95 \%$ specificity. MARTHIN and NiELSEN [17] had cut-offs of $64 \mathrm{~nL} \cdot \mathrm{min}^{-1}$ for breath hold (sensitivity $100 \%$, specificity $95.2 \%$ ) and $43 \mathrm{~nL} \cdot \mathrm{min}^{-1}$ for tidal breathing (sensitivity $100 \%$, specificity $100 \%$ ).

\section{Discussion}

This systematic review and meta-analysis confirms that $\mathrm{nNO}$ is significantly lower in PCD than in healthy individuals or patients with respiratory diseases including CF. Screening for PCD by measuring nNO during a velum closure manoeuvre is accurate with good sensitivity and specificity. Measurement of nNO during tidal breathing is relatively easy to perform in non-cooperative children and provides a reasonable screening test, but is less sensitive than velum closure. Healthy young children have much lower nNO than adults or older children and false positives during screening are, therefore, more common. Although most studies have used stationary chemiluminescence analysers, a handful of small studies suggest that portable analysers are reliable for measuring $\mathrm{nNO}$ as a screening test for PCD. It is important for those using portable analysers to understand the limitations of these devices. As well as differing in the means of analysis, portable analysers do not display the sampling in real-time so there is no way of checking the validity of the measurement (for example ensuring a steady plateau reading is taken). Plateau visualisation can ensure the reading is not affected by nares leak or lower airway contamination. NIOX portable versus stationary analysers are compared more fully by HARRIs et al. [32]. There is a need for standardised protocols and training at sites distant to the PCD diagnostic centre whether using portable or stationary analysers.

In assessing diagnostic accuracy of $\mathrm{nNO}$, choosing a cut-off nNO level that is three standard deviations from the mean would include all but $0.15 \%$ of PCD patients; using data from the meta-analysis (table 1 ) this cutoff is $75.2 \mathrm{~nL} \cdot \mathrm{min}^{-1}$. Individual studies suggested cut-offs ranging from 38 to $126 \mathrm{~nL} \cdot \mathrm{min}^{-1}$ (table 3), with the largest study $(\mathrm{n}=227)$ calculating that a cut-off of $77 \mathrm{~nL} \cdot \mathrm{min}^{-1}$ has sensitivity of $98 \%$ [42]; while MARTHIN and Nielsen [17] found a cut-off of $78.6 \mathrm{~nL} \cdot \mathrm{min}^{-1}$ provided them with a sensitivity of $100 \%$. $77 \mathrm{~nL} \cdot \mathrm{min}^{-1}$ is equivalent to $257 \mathrm{ppb}$ on NIOX Flex/MINO, $233 \mathrm{ppb}$ on Eco Medics CLD 88sp, $308 \mathrm{ppb}$ on LR2000 and $144 \mathrm{ppb}$ on Sievers. High sensitivity is important to select all PCD patients for further diagnostic testing, but it is important to note that the cut-off level of $77 \mathrm{~nL} \cdot \mathrm{min}^{-1}$ is for children $>5$ years of age and adults using velum closure manoeuvres. Further work is needed to establish cut-offs for younger children, for tidal breathing and for portable devices.

Respiratory manoeuvres during measurement are one of the topics requiring standardisation. For example, a variety of methods are used to achieve velum closure that is required for a "true" plateau measurement. Velum closure can be achieved during voluntary manoeuvres (making a "k" sound) or during breath hold, but is easier to achieve while blowing against a resistor. If a plateau is not reached the measures will be lower and the cut-off less discriminatory. This is demonstrated by results from MARTHIN and NIELSEN [25] where the cut-off for measurement during velum closure during exhalation against a resistor is higher than during breath hold (table 3).

Rarely patients with PCD have nNO levels in the normal range [19, 25]. MARTHIN and NieLSEN [25] examined the characteristics of the five subjects in their study with PCD and normal nNO, and found all had classical symptoms such as chronic wet cough and persistent nasal secretions from birth; all were subsequently discovered to have both beat frequency and ultrastructure abnormalities. This highlights need for PCD diagnostic testing in those with strong clinical suspicion even if $\mathrm{nNO}$ is normal.

A number of studies suggest that patients with CF have nNO concentrations that are lower than in healthy controls (tables 1 and 2). Although we have demonstrated that levels are generally greater than in PCD, occasional CF patients have nNO in a similar range to PCD patients $[19,25,26]$. This may be due to nasal polyposis [31], reduced levels of inducible nitric oxide synthase [43] or changes in arginine metabolism [44].

In the small numbers of patients studied, there remains a highly significant difference in nNO levels between PCD, CF and healthy groups measured during tidal breathing despite the influence of lower airway gas mixing (table 5), but the discrimination is poorer than measurement during velum closure $[17,19,25,32]$. Tidal breathing is the only option for screening younger children who are unable to cooperate with breathing manoeuvres; as nNO levels are lower in healthy children than healthy adults [37] false positive rates are as high as 39\% in children under 6 years of age [25]. However, PIACENTINI et al. [22] found a cutoff of $16.2 \mathrm{~nL} \cdot \mathrm{min}^{-1}$ was $90 \%$ sensitive for a PCD diagnosis in children less than 6 months of age. nNO measured during tidal breathing is, therefore, a useful adjunct to clinical suspicion in the screening of young children for PCD with good negative predictive value, but must be interpreted with caution and alongside clinical history, particularly in those under 12 months-old. It should be noted that children as young as 3 years of age were able to cooperate with velum closure in some studies [22], but in the experience of the authors, success is low in preschool children. 
The cost, maintenance and training required for stationary NO analysers has led to the development of handheld sensors. The studies comparing portable and stationary analysers are small, but suggest they are a reliable means of measuring $\mathrm{nNO}[17,32]$. ROC analysis by HARRIS et al. [32] and MARTHIN and NiELSEN [17] produced cut-offs of 30 and $64 \mathrm{~nL} \cdot \mathrm{min}^{-1}$, respectively (100 and $213 \mathrm{ppb}$ on NIOX, 91 and $194 \mathrm{ppb}$ on Eco Medics CLD88sp), for tidal breathing nNO via portable analyser; both achieving sensitivity of $100 \%$.

There were a number of limitations to the data available for the meta-analysis. The meta-analysis found a high degree of heterogeneity within and between studies; therefore, combining means and standard deviations must be interpreted with caution. The higher degree of heterogeneity in the healthy control comparison may reflect that most studies included children. This may skew results in controls, as STRUBEN et al. [45] reported that $\mathrm{nNO}$ is age related under 12 years of age and found the mean $\mathrm{nNO}$ in 6-17 year-olds to be $135 \mathrm{~nL} \cdot \mathrm{min}^{-1}$ (meta-analysis healthy control mean: $271.6 \mathrm{~nL} \cdot \mathrm{min}^{-1}$ ). Also, many studies report parametric summary statistics for an item that cannot be less than zero but with a relatively large standard deviation, and we have not been able to interrogate the source data to validate this assumption of normality. The studies that reported nonparametric summary statistics could not be incorporated into the meta-analysis. In addition, we converted a number of different sampling techniques into $\mathrm{nL} \cdot \mathrm{min}^{-1}$ values and, although there is some evidence that this is a valid conversion $[17,19]$, differing sampling rates may have different effects depending on the size of the nasal cavity and whether there is a patent sinus meatus with normally developed sinuses beyond.

In conclusion, there is strong evidence that $\mathrm{nNO}$ is reduced in PCD compared with healthy controls and other patient groups, supporting the international expansion of $\mathrm{nNO}$ as a screening test for PCD. Our review has demonstrated that measurement of $\mathrm{nNO}$ as a screening test is accurate using a variety of manoeuvres and analysers. Efforts are now needed to standardise the reporting of measurements. The review confirms the following. 1) $\mathrm{nNO}$ measurement during velum closure via breath hold or oral exhalation has the best discriminatory ability, but measurement during tidal breathing is simpler to perform. 2) A nNO level below $77 \mathrm{~nL} \cdot \mathrm{min}^{-1}$ (NIOX $257 \mathrm{ppb}$; Eco Medics $233 \mathrm{ppb}$; Sievers $144 \mathrm{ppb}$; and LR2000 $308 \mathrm{ppb}$ ) should be considered highly suggestive of PCD and warrants further assessment in a specialist diagnostic centre. However normal nNO levels are occasionally reported in PCD. Further studies are required to develop cut-offs for children $<5$ years of age, for tidal breathing and for portable devices. 3) nNO levels are low in those with "atypical" PCD, including those with normal ultrastructure on electron microscopy. 4) nNO levels are lower in all preschool children, therefore, they must be interpreted with the clinical picture. There are a high number of false positives, particularly in infants. 5) Readings using a handheld analyser appear to provide an accurate screening test for PCD patients, but the numbers of patients in these studies have been small, and experience from the clinical setting is now needed. The hand-held analyser that is currently available requires a long breath hold, with resultant poor success rates for obtaining a measurement using this manoeuvre. 6) Tidal breathing $\mathrm{nNO}$ measurement can be a useful adjunct in the screening of young children or adults who cannot cooperate with velum closure. It should be noted that the rate of false positive results appears high in infants, although data are sparse.

This review has demonstrated a lack of uniformity for methods and reporting. All methods to measure nNO provided good discrimination between PCD and non-PCD groups, but the accuracy of some methods was better than others. Moving forward, we advocate that evidence-based or consensus guidelines are urgently required for methods at different ages and in different clinical settings (e.g. specialist PCD centre versus satellite referral centre). This will be one of the areas for consideration by a newly commissioned ERS Task Force: Diagnosis of PCD in a molecular age: a practice guideline for diagnosing patients with PCD.

\section{References}

1 Lucas JSA, Walker WT, Kuehni CE, et al. Primary ciliary dyskinesia. In: Courdier J-F, ed. Orphan Lung Diseases. Eur Respir Monogr 2011; 54: 201-217.

2 Barbato A, Frischer T, Kuehni CE, et al. Primary ciliary dyskinesia: a consensus statement on diagnostic and treatment approaches in children. Eur Respir J 2009; 34: 1264-1276.

3 Kuehni CE, Frischer T, Strippoli M-PF, et al. Factors influencing age at diagnosis of primary ciliary dyskinesia in European children. Eur Respir J 2010; 36: 1248-1258.

4 Strippoli M-PF, Frischer T, Barbato A, et al. Management of primary ciliary dyskinesia in European children: recommendations and clinical practice. Eur Respir J 2012; 39: 1482-1491.

5 Lundberg JO, Weitzberg E, Nordvall SL, et al. Primarily nasal origin of exhaled nitric oxide and absence in Kartagener's syndrome. Eur Respir J 1994; 7: 1501-1504.

$6 \quad$ Karadag B, James AJ, Gültekin E, et al. Nasal and lower airway level of nitric oxide in children with primary ciliary dyskinesia. Eur Respir J 1999; 13: 1402-1405.

7 Narang I, Ersu R, Wilson NM, et al. Nitric oxide in chronic airway inflammation in children: diagnostic use and pathophysiological significance. Thorax 2002; 57: 586-589.

8 Horváth I, Loukides S, Wodehouse T, et al. Comparison of exhaled and nasal nitric oxide and exhaled carbon monoxide levels in bronchiectatic patients with and without primary ciliary dyskinesia. Thorax 2003; 58: 68-72.

9 Wodehouse T, Kharitonov SA, Mackay IS, et al. Nasal nitric oxide measurements for the screening of primary ciliary dyskinesia. Eur Respir J 2003; 21: 43-47. 
10 Corbelli R, Bringolf-Isler B, Amacher A, et al. Nasal nitric oxide measurements to screen children for primary ciliary dyskinesia. Chest 2004; 126: 1054-1059.

11 ATS/ERS recommendations for standardized procedures for the online and offline measurement of exhaled lower respiratory nitric oxide and nasal nitric oxide, 2005. Am J Respir Crit Care Med 2005; 171: 912-930.

12 Walker WT, Jackson CL, Lackie PM, et al. Nitric oxide in primary ciliary dyskinesia. Eur Respir J 2012; 40: 1024-1032.

13 Degano B, Valmary S, Serrano E, et al. Expression of nitric oxide synthases in primary ciliary dyskinesia. Hum Pathol 2011; 42: 1855-1861.

14 Smith CM, Kulkarni H, Radhakrishnan P, et al. Ciliary dyskinesia is an early feature of respiratory syncytial virus infection. Eur Respir J 2013; 43: 485-496.

15 Walker WT, Jackson CL, Coles J, et al. Ciliated cultures from patients with primary ciliary dyskinesia produce nitric oxide in response to Haemophilus influenzae infection and proinflammatory cytokines. Chest 2014; 145: 668-669.

16 Pifferi M, Bush A, Caramella D, et al. Agenesis of paranasal sinuses and nasal nitric oxide in primary ciliary dyskinesia. Eur Respir J 2011; 37: 566-571.

17 Marthin JK, Nielsen KG. Hand-held tidal breathing nasal nitric oxide measurement - a promising targeted casefinding tool for the diagnosis of primary ciliary dyskinesia. PLoS One 2013; 8: e57262.

18 Pizzimenti S, Bugiani M, Piccioni P, et al. Exhaled nitric oxide measurements: correction equation to compare hand-held device to stationary analyzer. Respir Med 2008; 102: 1272-1275.

19 Leigh MW, Hazucha MJ, Chawla KK, et al. Standardizing nasal nitric oxide measurement as a test for primary ciliary dyskinesia. Ann Am Thorac Soc 2013; 10: 574-581.

20 Csoma Z, Bush A, Wilson NM, et al. Nitric oxide metabolites are not reduced in exhaled breath condensate of patients with primary ciliary dyskinesia. Chest 2003; 124: 633-638.

21 Noone PG, Leigh MW, Sannuti A, et al. Primary ciliary dyskinesia: diagnostic and phenotypic features. Am J Respir Crit Care Med 2004; 169: 459-467.

22 Piacentini GL, Bodini A, Peroni D, et al. Nasal nitric oxide for early diagnosis of primary ciliary dyskinesia: practical issues in children. Respir Med 2008; 102: 541-547.

23 Shoemark A, Wilson R. Bronchial and peripheral airway nitric oxide in primary ciliary dyskinesia and bronchiectasis. Respir Med 2009; 103: 700-706.

24 Moreno Galdó A, Vizmanos Lamotte G, Reverte Bover C, et al. Valor del óxido nitrico nasal en el diagnóstico de la discinesia ciliar primaria [Value of nasal nitric oxide in the diagnosis of primary ciliary dyskinesia]. An Pediatr (Barc) 2010; 73: 88-93.

25 Marthin JK, Nielsen KG. Choice of nasal nitric oxide technique as first-line test for primary ciliary dyskinesia. Eur Respir J 2011; 37: 559-565.

26 Mateos-Corral D, Coombs R, Grasemann H, et al. Diagnostic value of nasal nitric oxide measured with non-velum closure techniques for children with primary ciliary dyskinesia. J Pediatr 2011; 159: 420-424.

27 Whiting P, Rutjes AWS, Reitsma JB, et al. The development of QUADAS: a tool for the quality assessment of studies of diagnostic accuracy included in systematic reviews. BMC Med Res Methodol 2003; 3: 25.

28 Harrison M, Barry J, Burke L, et al. The clinical utility of a hand-held nasal nitric oxide (NNO) electrochemical analyser to screen patients with bronchiectasis for primary ciliary dyskinesia (PCD) and cystic fibrosis (CF). Irish J Med Sci 2012; 181: Suppl. 10, S403-S404.

29 Santamaria F, De Stefano S, Montella S, et al. Nasal nitric oxide assessment in primary ciliary dyskinesia using aspiration, exhalation, and humming. Med Sci Monit 2008; 14: CR80-CR85.

30 Walker WT, Liew A, Harris A, et al. Upper and lower airway nitric oxide levels in primary ciliary dyskinesia, cystic fibrosis and asthma. Respir Med 2013; 107: 380-386.

31 Boon M, Meyts I, Proesmans M, et al. Diagnostic accuracy of nitric oxide measurements to detect primary ciliary dyskinesia. Eur J Clin Invest 2014; 44: 477-485.

32 Harris A, Bhullar E, Gove K, et al. Validation of a portable nitric oxide analyzer for screening in primary ciliary dyskinesias. BMC Pulm Med 2014; 14: 18.

33 Pifferi M, Bush A, Maggi F, et al. Nasal nitric oxide and nitric oxide synthase expression in primary ciliary dyskinesia. Eur Respir J 2011; 37: 572-577.

34 Pifferi M, Caramella D, Cangiotti AM, et al. Nasal nitric oxide in atypical primary ciliary dyskinesia. Chest 2007; 131: 870-873.

35 Knowles MR, Ostrowski LE, Leigh MW, et al. Mutations in RSPH1 cause primary ciliary dyskinesia with a unique clinical and ciliary phenotype. Am J Respir Crit Care Med 2014; 189: 707-717.

36 Kott E, Legendre M, Copin B, et al. Loss-of-function mutations in RSPH1 cause primary ciliary dyskinesia with central-complex and radial-spoke defects. Am J Hum Genet 2013; 93: 561-570.

37 Piacentini GL, Bodini A, Peroni DG, et al. Nasal nitric oxide levels in healthy pre-school children. Pediatr Allergy Immunol 2010; 21: 1139-1145.

38 Montella S, Alving K, Maniscalco M, et al. Measurement of nasal nitric oxide by hand-held and stationary devices. Eur J Clin Invest 2011; 41: 1063-1070.

39 Maniscalco M, Weitzberg E, Sundberg J, et al. Assessment of nasal and sinus nitric oxide output using single-breath humming exhalations. Eur Respir J 2003; 22: 323-329.

40 Baraldi E, Pasquale MF, Cangiotti AM, et al. Nasal nitric oxide is low early in life: case study of two infants with primary ciliary dyskinesia. Eur Respir J 2004; 24: 881-883.

41 Stehling F, Roll C, Ratjen F, et al. Nasal nitric oxide to diagnose primary ciliary dyskinesia in newborns. Arch Dis Child Fetal Neonatal Ed 2006; 91: F233.

42 Baker BR, Chawla KK, Hazucha M, et al. Toward standardization of nasal nitric oxide testing for primary ciliary dyskinesia. Am J Respir Crit Care Med 2011; 183: A1210.

43 Moeller A, Horak F Jr, Lane C, et al. Inducible NO synthase expression is low in airway epithelium from young children with cystic fibrosis. Thorax 2006; 61: 514-520.

44 Grasemann H, Schwiertz R, Grasemann C, et al. Decreased systemic bioavailability of L-arginine in patients with cystic fibrosis. Respir Res 2006; 7: 87.

45 Struben VMD, Wieringa MH, Mantingh CJ, et al. Nasal NO: normal values in children age 6 through to 17 years. Eur Respir J 2005; 26: 453-457. 